\title{
miR-28 modulates exhaustive differentiation of T cells through silencing programmed cell death-1 and regulating cytokine secretion
}

\author{
Qing Li ${ }^{1,2, *}$, Nathan Johnston ${ }^{3, *}$, Xiufen Zheng ${ }^{3,4}$, Hongmei Wang ${ }^{1}$, Xusheng Zhang ${ }^{3}$, \\ Dian Gao ${ }^{1}$, Weiping Min ${ }^{1,4}$ \\ ${ }^{1}$ Institute of Immunotherapy of Nanchang University, and Jiangxi Academy of Medical Sciences, Nanchang, China \\ ${ }^{2}$ Department of Oncology, the Second Affiliated Hospital of Nanchang University, Nanchang, China \\ ${ }^{3}$ Department of Surgery, Pathology and Oncology, Western University, London, Canada \\ ${ }^{4}$ Lawson Health Research Institute, London, Canada \\ *These authors have contributed equally to this work \\ Correspondence to: Weiping Min, email: weiping.min@uwo.ca \\ Xiufen Zheng, email: xzheng26@uwo.ca \\ Keywords: exhausted T cells, miR-28, inhibitor receptors, PD 1, melanoma
}

Received: April 21,2016 Accepted: June 13,2016 Published: July 20, 2016

\section{ABSTRACT}

T cell exhaustion is a state of $\mathbf{T}$ cell dysfunction that arises during many cancer. miRNAs are one of major gene regulators which result in translational inhibition and/ or mRNA degradation. We hypothesized that miRNAs exist that can silence PD1 and act as a modulator in vitro to revert exhaustive status of $\mathrm{T}$ cells. We demonstrated that the exhausted $\mathrm{T}$ cells with inhibitory receptors (IRs) are significantly increased in the melanoma-bearing mice. Meanwhile, the differentiated miRNA profiles in PD1+ exhaustive $T$ cells were identified using a miRNA array; 11 miRNAs were observed with significant altered levels in the exhausted $T$ cells isolated from melanomabearing mice. Among those identified miRNA candidates, miR-28 was capable of binding to multiple IRs based on an in silico analysis and subsequently silencing PD1, as demonstrated by a dual luciferase assay. Moreover, the expression of PD1 was attenuated after transfection with miR-28 mimic. The ability of miR-28 in regulating $T$ cell exhaustion was further evidenced by the fact that the expression of PD1, TIM3 and BTLA of exhausted T cells was increased by the inhibitor of miR28. On the other hand, miR-28 also regulated the PD1+ Foxp3+ and TIM3+ Foxp3+ exhaustive Treg cells in vitro. miR-28 regulating $T$ cell exhaustion was also observed by its ability in reinstalling impaired secretion of cytokines IL-2 and TNF-a by exhausted T cells. This study is the first to discover the effect of miR-28 on T cell exhaustion, providing novel targets with potential use as therapeutic markers in cancer immunotherapy.

\section{INTRODUCTION}

Exhausted $\mathrm{T}$ cells were found in chronic viral infections and cancer, different inhibitory receptors were expressed increasing in those exhausted $\mathrm{T}$ cells with functional deficiency $[1,2]$. Many inhibitory receptors such as programmed death-1 (PD1), T-cell immunoglobulin domain and mucin domain 3 (TIM3), B- and T-lymphocyte attenuator (BTLA), lymphocyte-activation gene 3 (LAG3), 2B4 (CD244), CD160, cytotoxic T lymphocyte antigen-4 (CTLA) are high-expressed on exhausted T cells during chronic infection [3, 4]. Dysfunctional tumor infiltrating T lymphocytes were also found to co-express PD1, LAG3[5] and TIM3[6]. PD1 is thought to be the most important cell surface inhibitory receptor among these molecules [7]. PD1 interacts with two ligands, programmed death ligand 1/2 (PD-L1/2) [8]. Interaction of PD1 with PD-L1/2 may negatively regulate cytokine secretion and $\mathrm{T}$ cells proliferation $[7,9]$.

Blocking the PD1 pathway is a new approach for treatment of tumor [10]. Studies on anti-PD1 antibodies (Nivolumab, Pembrolizumab, Pidilizumab and AMP- 
224) in various cancers including melanoma have entered clinical trials since late 2008[11, 12]. Ultimately, research on blockade of the PD1 or PD-L1, holds much promise with greater response rates and lower toxicity due to the tumor-specific mode of activation rather than generalized suppression of $\mathrm{T}$ cell inhibition [13]. A review of the anti-PD1 and anti-PD-L1 antibodies currently in clinical trials shows encouraging response rates of between $20 \%$ $50 \%$ that have continued after treatment, and acceptable transient low-grade immune-related adverse effects [14]. Although PD1 antibodies are demonstrating significant benefits in melanoma treatment, no one has attempted to observe the effects of microRNA (miRNA) regulation in the PD1 pathway.

miRNAs are short (approximately 22 nucleotides) RNAs that regulate gene expression by binding to the 3' untranslated regions (3' UTR) of mRNAs, it will lead to translational inhibition or mRNA degradation [15]. miRNAs do not have perfect complementarity when in the double stranded stem loop or to the mRNA targets, which allows one miRNA to bind several mRNA transcripts. It is now believed that, in humans, over $1000 \mathrm{miRNAs}$ regulate over $30 \%$ of our genome [16]. miRNAs originate from miRNA genes or introns of protein coding genes and, after processing by Drosha and Dicer, the miRNA is loaded into the RISC complex and oriented to the 3' UTR of mRNAs, thus inducing repression of protein expression through mRNA degradation or translational inhibition $[17,18]$.

Overall, no experimental research has been done to observe the effects of miRNAs on PD1 in melanoma and T cell exhaustion. In this study we show valuable epigenetic data on the immunoinhibitory target PD1, which supports the use of miRNAs as prognostic markers and therapeutic molecules to confer $\mathrm{T}$ cell immunity against melanoma. We further describe miRNAs that can regulate PD1, and that in vitro transfection of miR-28 mimics acts therapeutically to reduce exhausted $\mathrm{T}$ cells and regulate the cytokine secretion in the tumor microenvironment.

\section{RESULTS}

\section{Increased levels of exhaustion phenotype in $T$ cells isolated from lymphoid and spleen in murine melanoma model}

To confirm the $\mathrm{T}$ cell exhaustion in cancer, we first examined the expression of IRs such as PD1, TIM3, BTLA, 2B4 and LAG3 in T cells isolated from mice borne with B16F10 murine melanoma. C57BL/6 mice were inoculated subcutaneously with $4 \times 10^{5}$ B16F10 cells on their backs, tumors were allowed to grow for 16 days before isolating lymphocytes from draining lymph nodes and spleen. Next, flow cytometer was used to detected the IRs levels (PD1, TIM3, BTLA, 2B4, LAG3) in T cellcontaining tissues between naive and B16F10-bearing mice. PD1, TIM3, BTLA, 2B4, LAG3 were markedly increased in both CD4+ and CD8+ T cells of B16F10 tumor-bearing mice compared to naive mice (Figure 1). The CD4+PD1+ level was increased in draining lymph node $(19 \%)$ than naïve mice $(9 \%)$. CD4+TIM3+ was increased from $12 \%$ (naïve lymph nodes) to $19 \%$ (draining lymph node), other IRs phenotype such as $\mathrm{CD} 4+\mathrm{BTLA}+(38 \%), \mathrm{CD} 4+2 \mathrm{~B} 4+(35 \%), \mathrm{CD} 4+\mathrm{LAG} 3+$ $(27 \%)$ was also increased in draining lymph node of melanoma-bearing mice than naïve mice (Figure 1A). The exhausted phenotype of tumor bearing mice spleen were also detected. The similar growth was also found in the spleen T cells (Figure 1B). The IRs of CD8+ T cells were also have higher expression than in the naïve mice (Figure 1C-1D). These data suggested that the melanoma microenvironment has a significant impact on $\mathrm{T}$ cells exhaustion marker expression in the lymphoid and spleen tissue, the percentage of exhausted $\mathrm{T}$ cell was increasing when animals bear tumor.

\section{Differentiation of miRNA profiles between CD4+PD1- and CD4+PD1+ T cells isolated from tumor-bearing mice}

To analyze the miRNA expression profile between PD1+ and PD1- T cells, PD1+ and PD1- CD4+ T cells were sorted from lymph nodes and spleen of tumorbearing mice using a FACS Aria III, and total RNA including miRNA was extracted. Using the Affymetrix GeneChip 3.0 miRNA array no significant differences were found between the miRNA level profiles of either tissue, so the data from the both tissues were pooled. A heatmap was generated looking at miRNAs with a fold change of $+/-2.0$, which found 11 miRNAs significantly downregulated and another 8 significantly upregulated in CD4+PD1+ $\mathrm{T}$ cells in comparison with CD4+PD1$\mathrm{T}$ cells (Figure 2A). In order to confirm the results of miRNA array, RT-qPCR analysis on these 19 miRNAs was performed. Figure2B displays discrepancies between the miRNA array and RT-qPCR data, showing that only 3 down-regulated miRNAs (miR-150, miR-28 and miR151-5p) and 8 upregulated miRNAs (miR-let-7e, miR103, miR-107, miR-27a, miR-23a, miR-21, miR-155 and miR-146a) showed similar trends in altered miRNA levels. miR-28, miR-150, and miR-151-5p levels in CD4+PD1+ T cells decreased by $30 \%, 45 \%$, and $25 \%$, respectively (Figure 2C). The results imply that the levels of at least 11 miRNAs are altered as either a cause or a consequence of increased PD1 in a B16F10-derived tumor.

\section{In silico analysis and a dual luciferase assay of miRNAs that may bind to the 3' UTR of PD1}

To discover miRNAs that may bind to the 3' UTR of PD1, TIM3, and BTLA, an in silico database search was conducted using miRanda, TargetScan, PicTar 
and microRNA (Figure 3). The sequences of all known conserved miRNAs were compared with that of the 3' UTRs to discover areas of complementarity. Based on the base pairing in the seed region and other parts of the miRNA one can determine if a miRNA has the potential to bind to the 3' UTR and prevent protein expression. Among the 11 miRNAs confirmed by RT-qPCR, miR-28 have significant complementarity to the 3'UTR of all 3 inhibitory immunoreceptor theoretically (Figure 3A). To determine whether miR-28 could silence PD1 through its 3' UTR, a dual luciferase assay was conducted. The 3' UTR of PD1 was amplified from wild-type C57BL/6 lymph node cells and inserted into the pmirGLO Dual Luciferase miRNA target expression vector directly downregulate of firefly luciferase [19]. B16F10 cells were used to transfect the dual luciferase plasmids with miR-28 mimic or control miRNA, cells were collected and analyzed for firefly and renilla luciferase activity 24 hrs later. miR-28 reduced luciferase activity by $50 \%$ (Figure 3B). These data indicate that miR-28 can reduce gene expression through the 3' UTR of the PD1 gene. Therefore, in accordance with in silico and the dual luciferase assay, miR-28 was chosen as a candidate to determine if a miRNA can silence PD1 and regulate T cell function.

\section{Increased expression of inhibitory receptors in the in vitro-generated exhaustive $T$ cell}

Since the naturally low levels of PD1 on T cells from wild-type C57BL/6 lymphoid tissue makes it difficult to demonstrate miRNA-induced silencing, an in vitro system was needed that could upregulate inhibitory immunoreceptor levels. CD3e stimulation
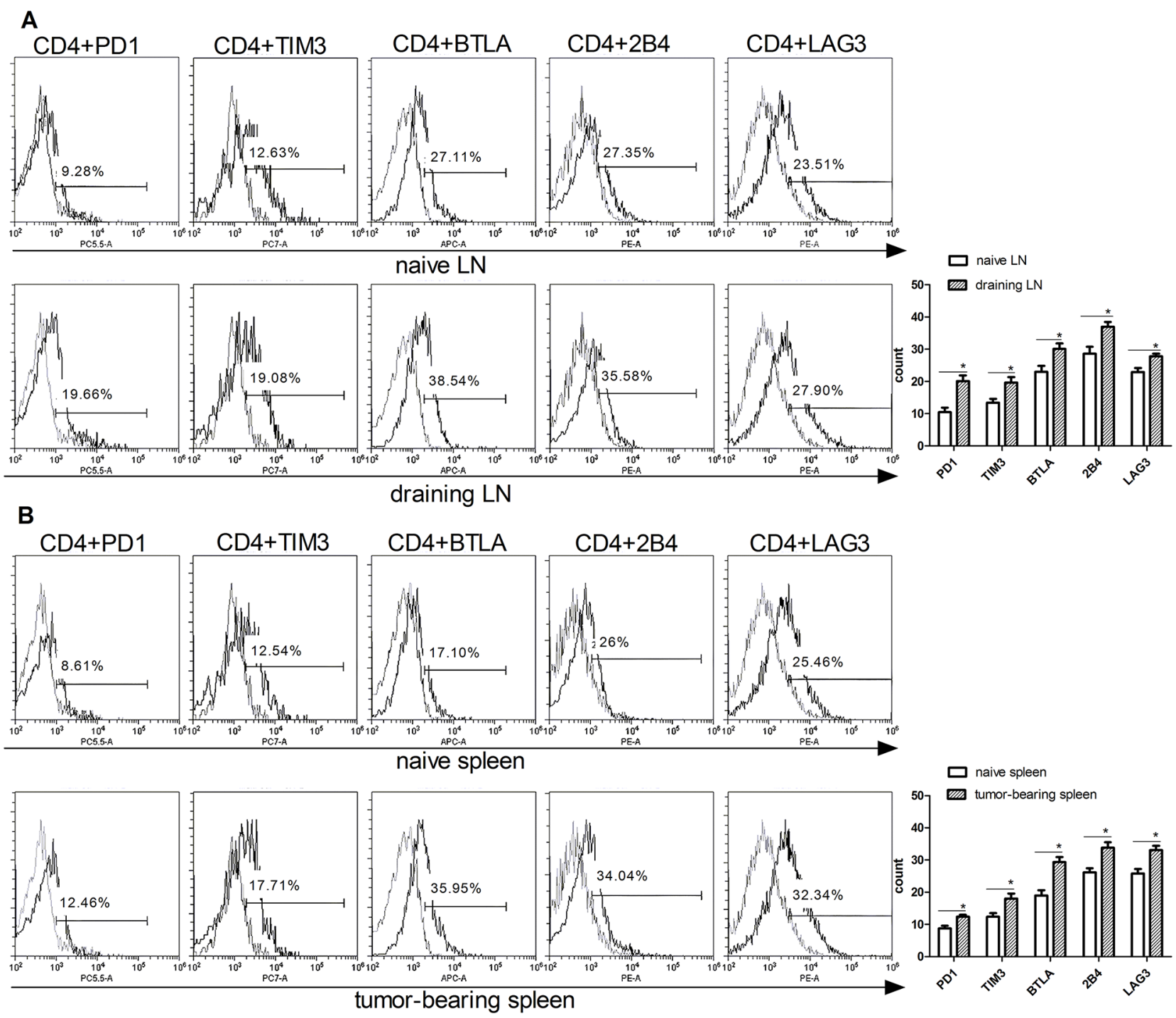

Figure 1: Upregulation of exhausted $\mathrm{T}$ cells phenotype in CD4 and CD8 $\mathrm{T}$ cells isolated from tumor-bearing mice. T cells were isolated from the lymph nodes (naïve LN) and spleen (naïve spleen) of wild type mice, or draining lymph nodes (DLN), and spleen (T spleen) of B16F10-bearing mice. Exhausted T cell phenotypes (PD1, TIM3, BTLA, 2B4, LAG3) on CD4 A. and B. and CD8. (Continued) 


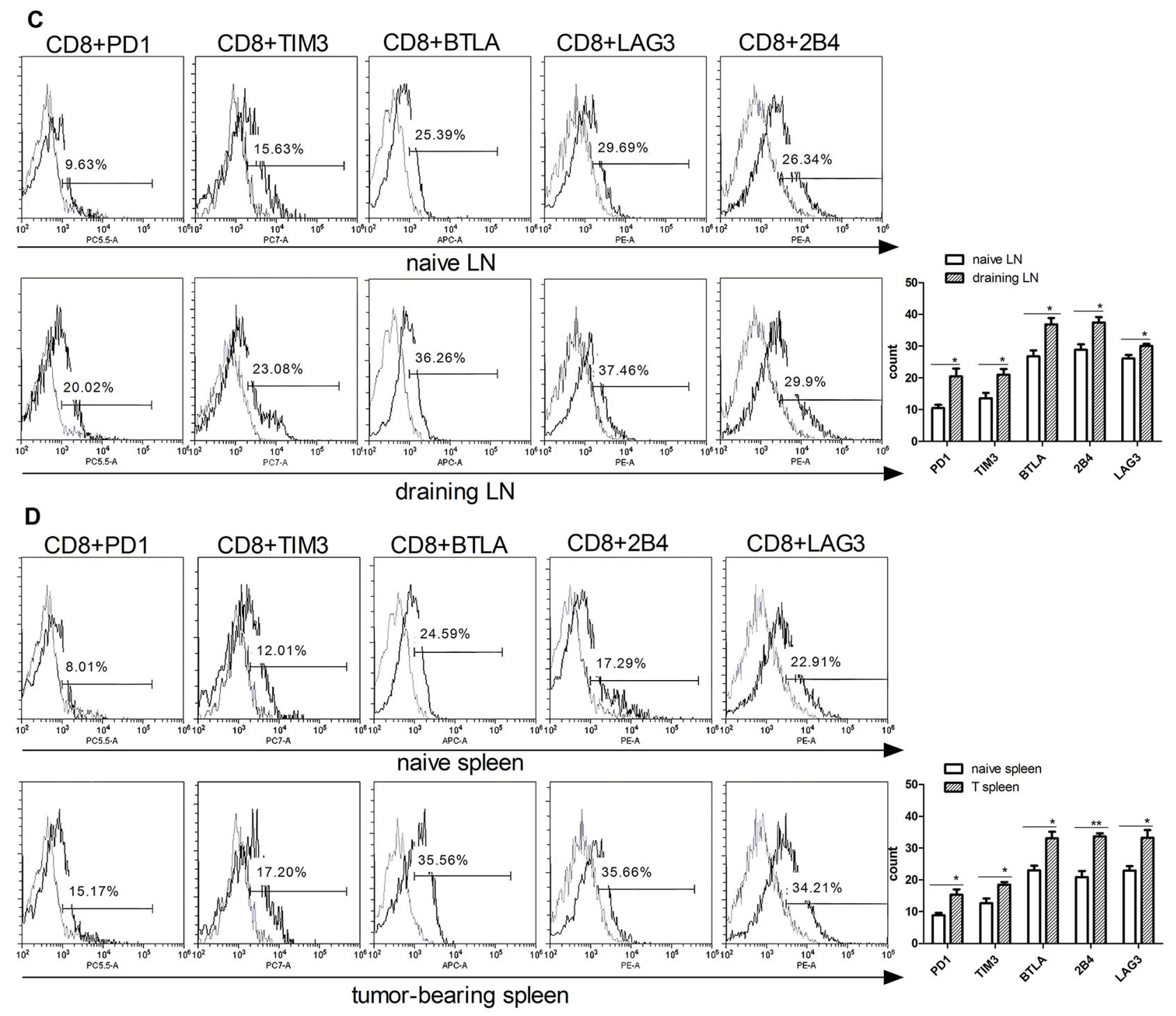

Figure 1: (Continued) Upregulation of exhausted T cells phenotype in CD4 and CD8 T cells isolated from tumorbearing mice. C. and D. T cells were analyzed by flow cytometry. Statistic analysis of the expression of PD1, TIM3, BTLA, 2B4, LAG3 levels in CD4 (right panel in A and B) and CD8 (right panels in C and D) were performed from three independent experiments. Significance was assumed if the $P$ value was less than $0.05(*=P<0.05, * *=P<0.01)$.

alone without $\mathrm{CD} 28$ co-activation signal causes the $\mathrm{T}$ cell to undergo anergy, a very similar process to $\mathrm{T}$ cell exhaustion. In addition, previous research has shown that IFN- $\alpha$-stimulated cells in the tumor expressed high levels of PD1[20]. Two methods were attempted in our research: culturing lymphocytes on anti-CD3e coated plates or anti-CD3e coated plates supplemented with IFN- $\alpha$ (antiCD3e+IFN- $\alpha$ ). $2 \times 10^{6}$ lymphocytes were plated in each well of 24 well plates that were coated with $0,1,10$, or $20 \mu \mathrm{g} / \mathrm{ml}$ of anti-CD3e overnight, with or without IFN- $\alpha$ $(10 \mathrm{ng} / \mathrm{ml})$ in cell culture medium, different concentrations of anti-CD3e $(0,1,10$, or $20 \mu \mathrm{g} / \mathrm{ml})$ coating plate with an addition of CD28 co-activation as control. Cells were cultured for $24 \mathrm{hrs}$ and analyzed by flow cytometry. Both Anti-CD3e and Anti-CD3e+ IFN- $\alpha$ treatment significantly increased exhaustion phenotype on CD4 (Figure 4A-4E) and CD8 $\mathrm{T}$ cells (Figure 4F-4J). There was no significant different between $10 \mu \mathrm{g} / \mathrm{ml}$ and $20 \mu \mathrm{g} / \mathrm{ml}$ group. Therefore, $10 \mu \mathrm{g} / \mathrm{ml}$ of anti-CD3e was used for subsequent experiments.

\section{miR-28 regulating the gene expression of PD1, TIM3 and BTLA}

To investigate the function of miR-28 to regulate the expression of IRs, T cells isolated from B16F10-bearing mice was transfected with miR-28 mimic or inhibitor. RT-qPCR was applied to test the gene expression of PD1, TIM3 and BTLA. The PD1 gene expression was decreased after transfection with miR-28 mimic (Figure 5A). On 


\section{A}
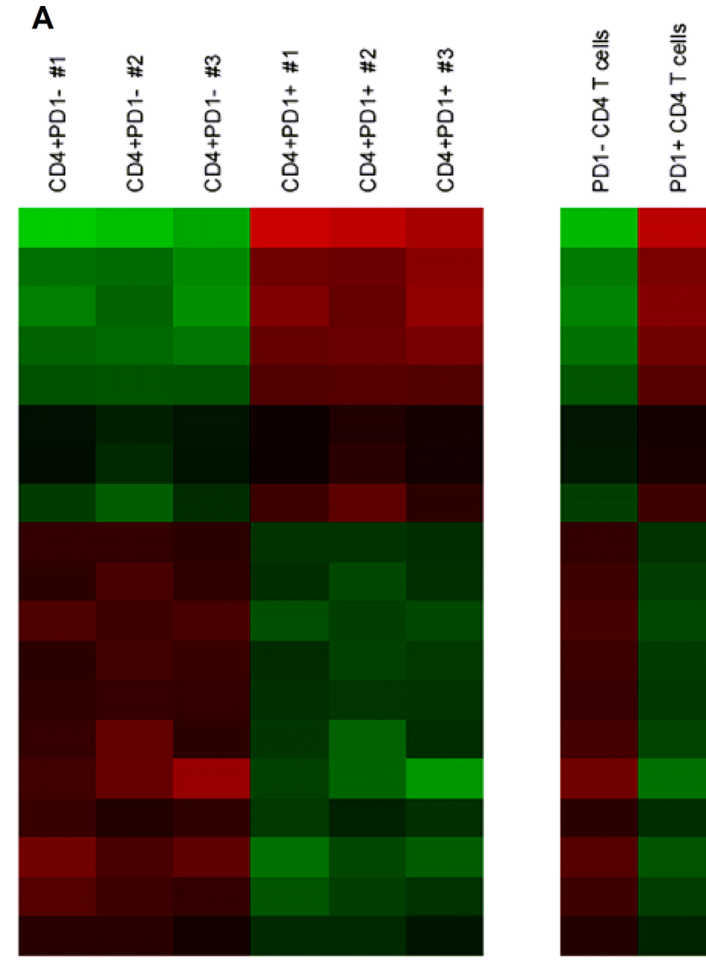

$-9.0$

0.0

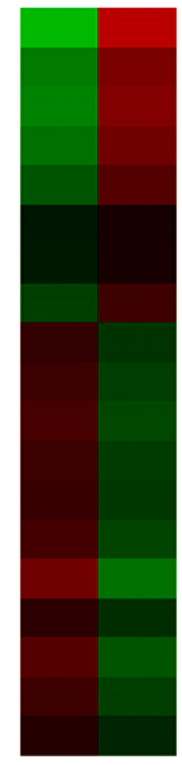

mmu-miR-146a

mmu-miR-155

mmu-miR-21

mmu-miR-23a

mmu-miR-27a

mmu-miR-107

mmu-miR-103

mmu-let-7e

mmu-miR-669a-5p

mmu-miR-30b

mmu-miR-467a

mmu-miR-466c-5p

mmu-miR-378b

mmu-miR-669a-3p

mmu-miR-5121

mmu-miR-181a

mmu-miR-151-5p

mmu-miR-28

mmu-miR-150
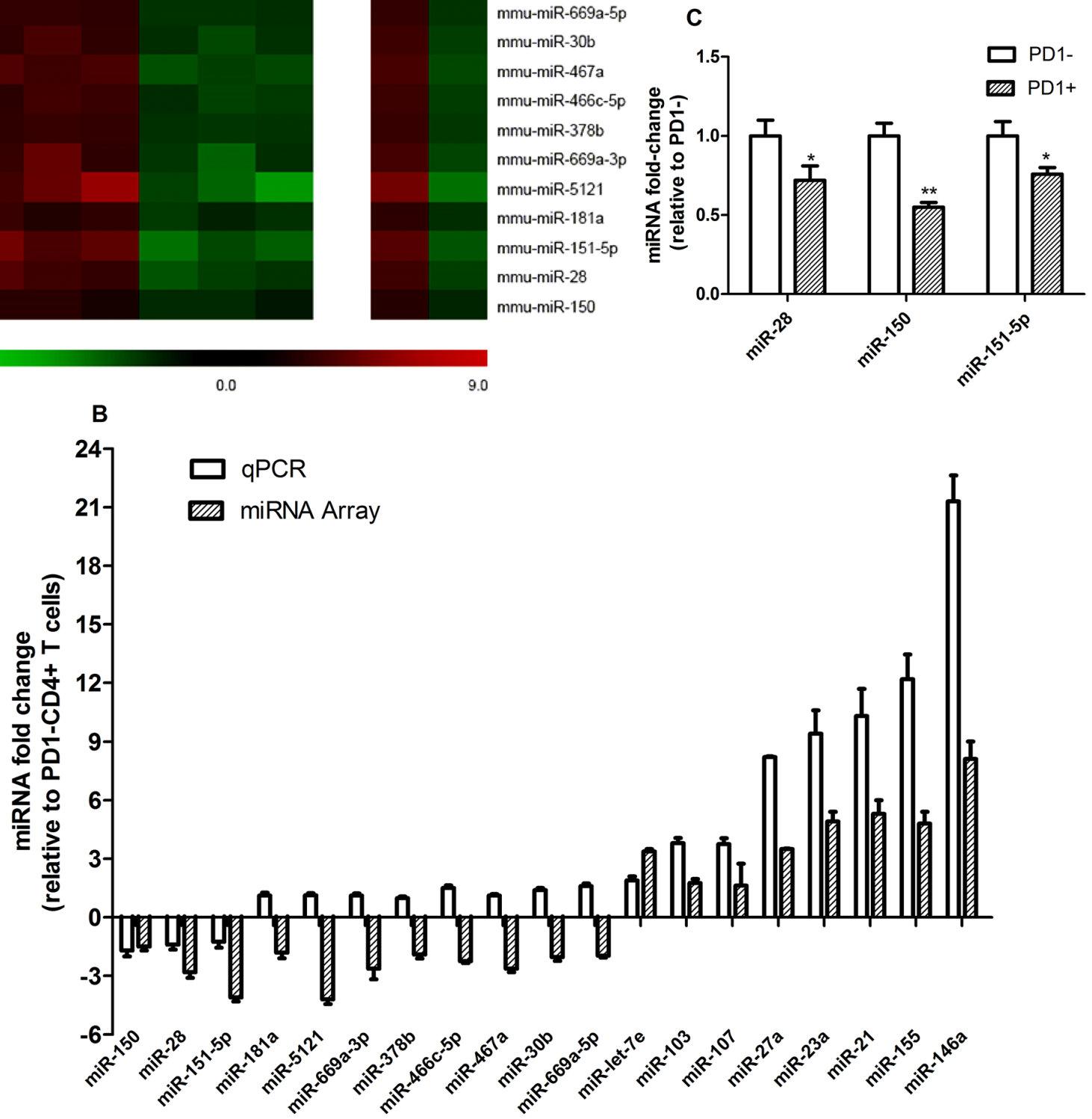

Figure 2: Global miRNA level profile between CD4+PD1- and CD4+PD1+ T cells isolated from tumor-bearing mice. A. Using the Affymetrix GeneChip 3.0 miRNA Array, a total of 1,966 mouse miRNAs were analyzed in PD1+ and PD1- CD4+ T cells. The heat maps represent 19 miRNAs with a fold change greater than +/- 2.0 between CD4+PD1- and CD4+PD1+ samples. The left heat map shows fold changes between $\mathrm{CD} 4+\mathrm{PD} 1-$ and $\mathrm{CD} 4+\mathrm{PD} 1+\mathrm{T}$ cells from three individual experiments, and the right heat map shows the average fold-change. B. In order to discover discrepancies between the miRNA array and RT-qPCR data, fold-changes were compared and only the miRNAs with equal trends were considered for further study. C. Significantly down regulated miRNAs in PD1+CD4+ T cells. $*=P<0.05, * *=P<0.01$ and $* * *=P<0.001$. The data shown are representative of at least three independent experiments. 
the contrary, the expression of PD1, TIM3 and BTLA were increased after transfection with miR-28 inhibitors (Figure 5A-5C). These data suggest that miR-28 is capable of regulating the PD1, TIM3 and BTLA genes on the $\mathrm{T}$ cell from melanoma-bearing mice.

\section{miR-28 manipulating exhaustive phenotype of $T$ cells}

Next, we investigated the function of miR-28 in regulating the exhausted phenotype. Flow cytometry was used to detect the exhaustion phenotype levels (PD1, TIM3, BTLA) in CD4+ or CD8+ T cell. After transfection with miR-28 mimic, PD1+ T cells were decreased from $38.3 \%$ to $28.21 \%$ in CD4+ T cells (Figure 6A) and from $36.91 \%$ to $28.5 \%$ in CD8+ T cells (Figure 6D), but TIM3 and BTLA had no significant decrease (Figure 6B, 6C, $6 \mathrm{E}, 6 \mathrm{~F})$. On the contrary, when transfected with miR-28 inhibitor, the PD1+ or TIM3 + T cells were increased both in the CD4+ (Figure 6A, 6B) and CD8+ T cells (Figure $6 \mathrm{D}, 6 \mathrm{E})$. These results highlighted that miR-28 can convert the exhaustive phenotype of PD1+ T cells.

\section{miR-28 modulating FoxP3+PD1+ and Foxp3+TIM3+ Treg cells}

It has been reported that Treg cells also undergo exhaustive differentiation, although it is controversial of the function of exhaustive Treg in tumor immunity [21]. It also remains largely unknown how exhaustive Treg cells are regulated. To clarify whether miR-28 is involved in the process of exhaustive differentiation of Treg cells, $\mathrm{T}$ cells isolated from spleen of B16F10-bearing mice, after transfected with miR-28 mimic or inhibitor in vitro with anti-CD3e coating plates, flow cytometry was used detected the conventional CD4+CD25+Foxp3+ Treg, as well as "exhaustive" Foxp3+PD1+ and Foxp3+TIM3+ Treg cells (Figure 7). The miR-28 mimic can decrease the expression of the Foxp3+PD1+ T cells. The Foxp3+PD1+ (Figure 7B) and Foxp3+TIM3+ cells (Figure 7C) were increased after transfected with miR-28 inhibitor. However, no significantly statistical difference was found in the conventional CD4+CD25+Foxp3+ Treg (Figure 7A) was found. Taken together, these data indicate that miR-28 may regulate PD1 and TIM3 expression in vitro partially.

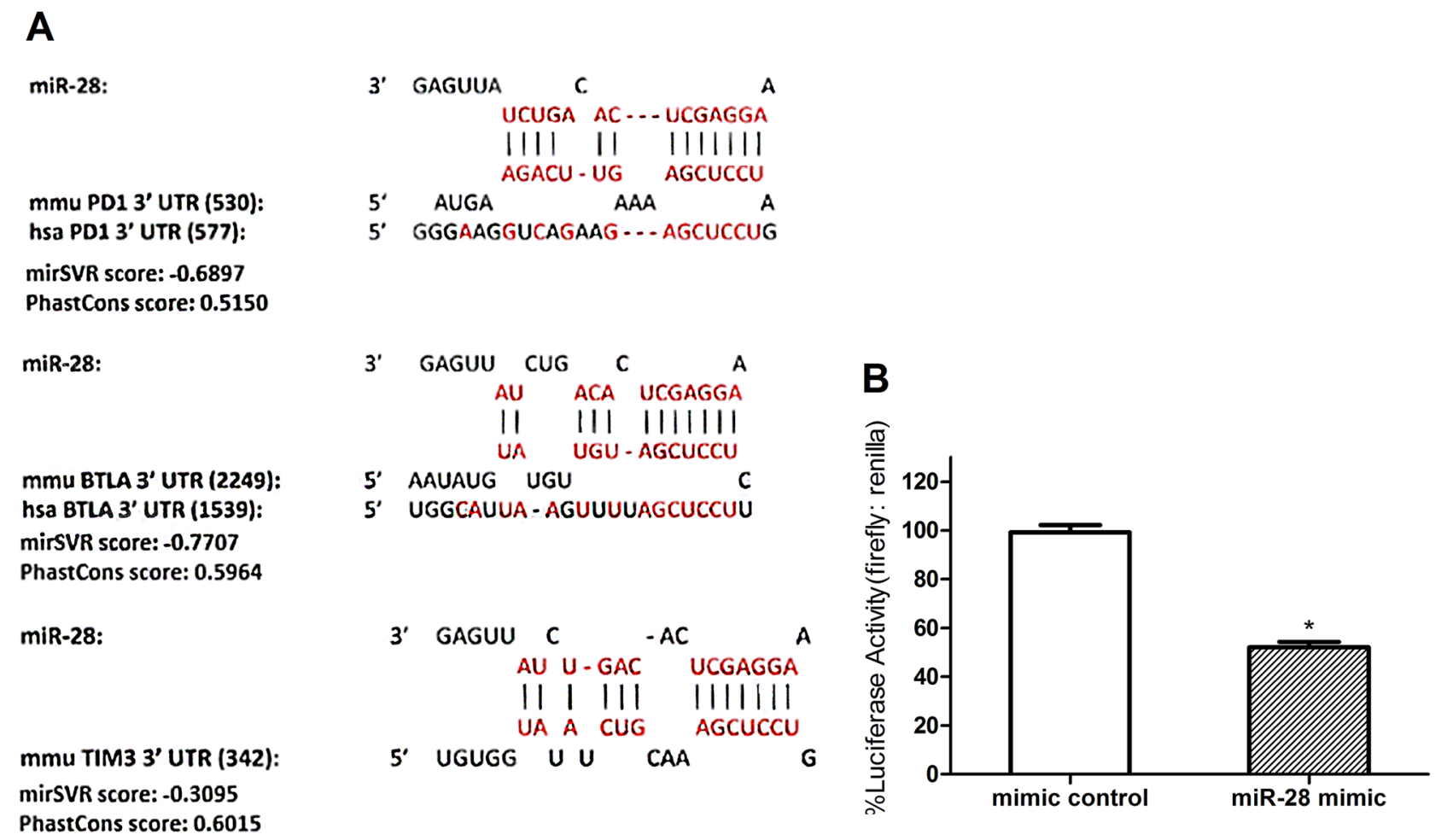

Figure 3: Defining the potential targets of exhaustion-associated inhibitory receptors PD1 by miR-28. A. In silico analysis using miRanda, TargetScan, PicTar and microRNA to discover miRNA candidates that may silence PD1, TIM3, and BTLA in various combinations. The theoretical bindings sites for miR-28 on the 3' UTR of PD1, BTLA and TIM3. Each miRNA-mRNA combination displays the miRNA, murine 3' UTR and human 3' UTR sequences from top to bottom. The vertical lines represent base-pairing between the miRNA and the murine ( $\mathrm{mmu}$ ) 3' UTR. The number in the bracket denotes the distance in nucleotides from the start of the 3' UTR to the start of the miRNA seed region. All the mirSVR score $<-0.1$ and PhastCons score $>0.5$. B. A Dual Luciferase Assay using pmirGLO Plasmid with PD1 3' UTR insert and miRNA mimics. B16F10 cells were transfected with the PD1 3' UTR dual luciferase plasmid and miR-28 mimic. Luciferase Activity was measured with a luminometer and normalized to mimic control. $\mathrm{T}$ test was used compared to the mimic control. Significance was assumed if $P<0.05(*=P<0.05)$. The data shown are representative of three independent experiments. 

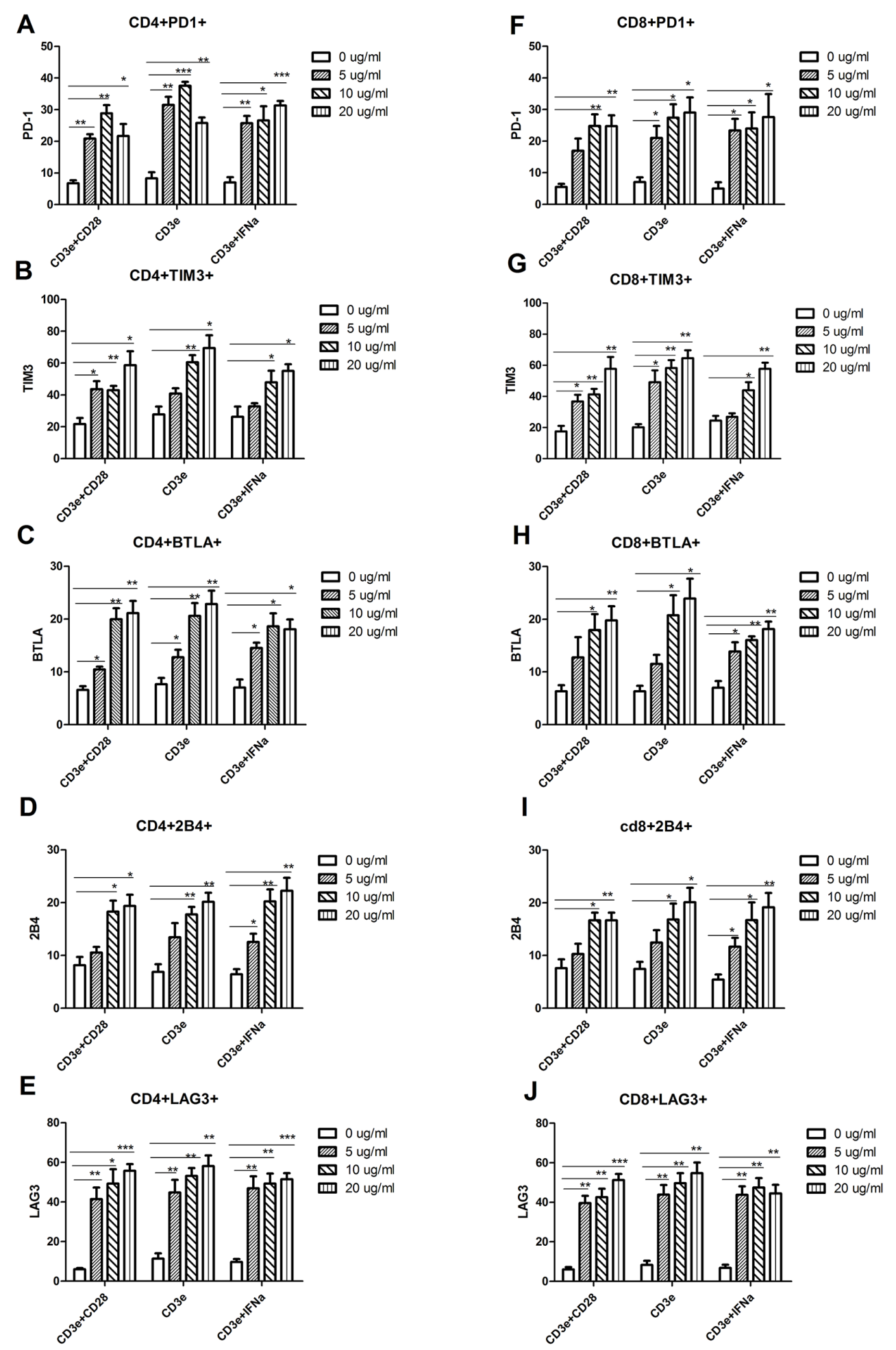

Figure 4: Increased expression of inhibitory receptors in the in vitro-generated exhaustive $\mathbf{T}$ cell. Lymphocytes isolated from the lymph node of wild type C57BL/6 mice were cultured on anti-CD3e coating plates for $24 \mathrm{hrs}$, in the presence or absence of CD28 $(1 \mu \mathrm{g} / \mathrm{ml})$ or IFN- $\alpha(10 \mathrm{ng} / \mathrm{ml})$. A-E. CD4+ T Cells were stained with PD1, TIM3, BTLA, $2 \mathrm{~B} 4$ and LAG3 mAb, respectively, as described in Materials and Methods. F-J. CD8+ T Cells were stained with PD1, TIM3, BTLA, 2B4 and LAG3 mAb, respectively, as described above. The subsets of CD4+PD1 (A), CD4+TIM3 (B), CD4+BTLA (C), CD4+2B4 (D) and CD4+LAG3 (E) expression, as well as the subsets of CD8+PD1 (F), CD8+TIM3 (G), CD8+BTLA (H), CD8+2B4 (I) and CD8+LAG3 (J) were analyzed by flow cytometry. For all T cell subtypes, a one-way analysis of variance followed by a Dunnett's multiple comparison test was used to compare exhaustion phenotype between treatment and no treatment with CD3e, CD28 and IFN- $\alpha$. Significance was assumed if the $P$ value was less than $0.05\left(^{*}=P<0.05\right.$, $* *=P<0.01$ and $* * *=P<0.001)$. The date shown are representative of three independent experiments. 

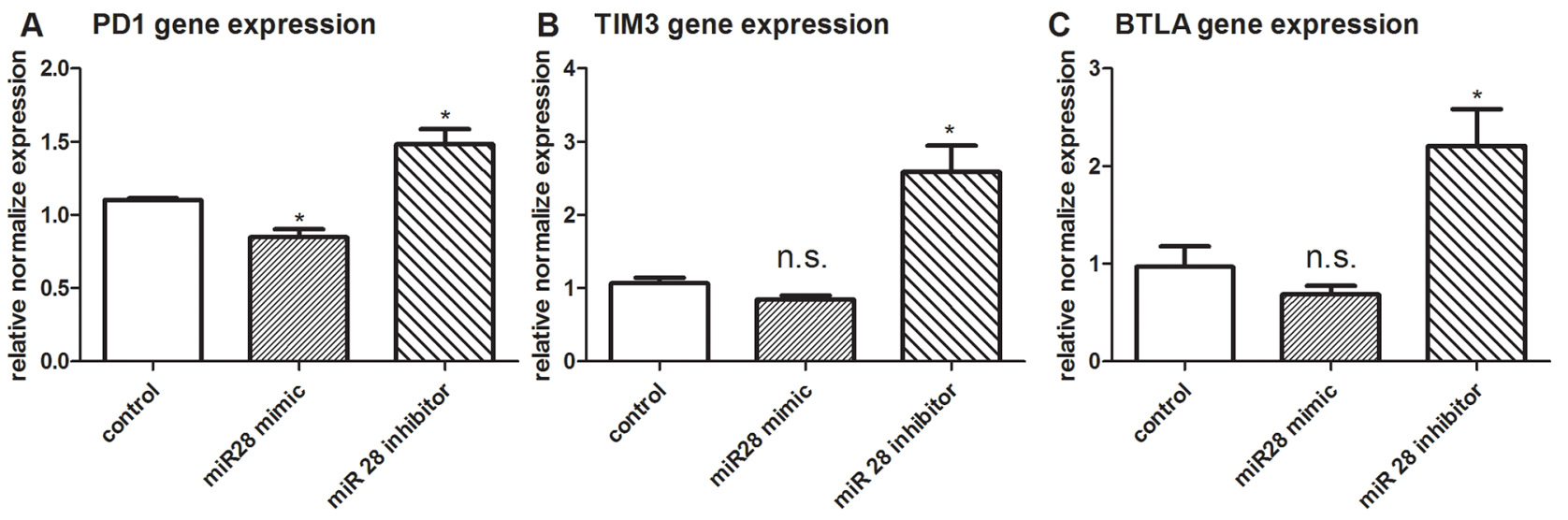

Figure 5: PD1, TIM3, BTLA gene expression after transfection with miR-28 mimic or miR-28 inhibitor. Two million lymphocytes, collected from lymph nodes of B16F10-bearing mice, were transfected with $1 \mu \mathrm{g}$ of miR-28 mimic or miR-28inhibitor, then cells were made exhaustive by the culture with anti-CD3e $(10 \mu \mathrm{g} / \mathrm{ml})$ coating plates for $72 \mathrm{hrs}$. The expression of PD1 A. TIM3 B. and BTLA C. were detected by qPCR. T test was used for the miRNA gene expression compared to the control group. Significance was assumed if the $P$ value was less than 0.05 ( $*=P<0.05$ ), n.s. (not significant) means $P$ value was more than 0.05 . The data shown are representative of at least three independent experiments.
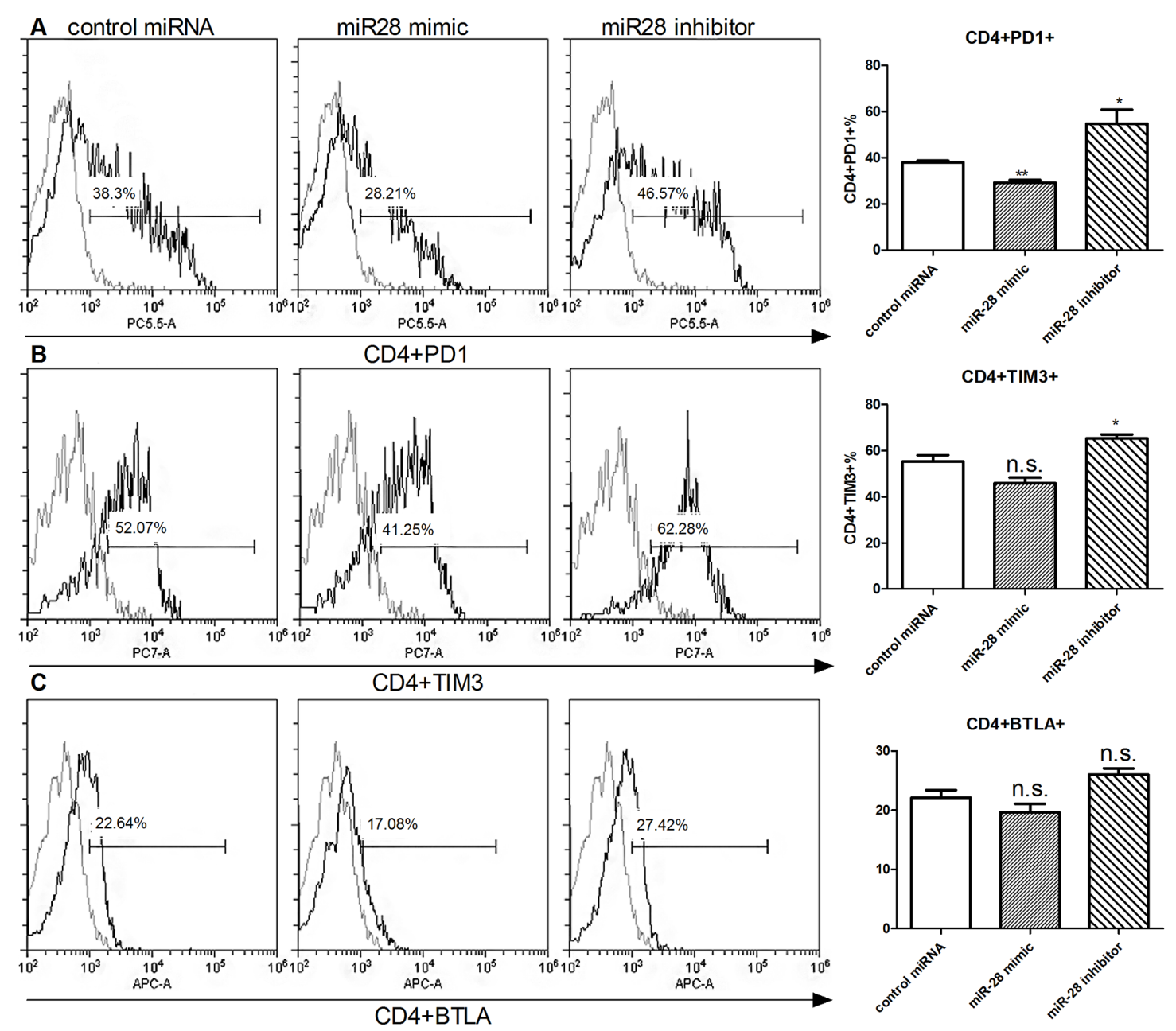

Figure 6: Alteration of exhaustive phenotype of $\mathrm{T}$ cells after transfection of miR-28 mimic and miR-28 inhibitor. Two million lymphocytes, collected from lymph nodes of B16F10-bearing mice, were plated per well in a 24 well plate and transfected with $1 \mu \mathrm{g}$ of miR-28 mimic or miR-28 inhibitor, then cells were cultured in anti-CD3e $(10 \mu \mathrm{g} / \mathrm{ml})$ coating plates for $72 \mathrm{hrs}$. Flow cytometric analysis were performed to determine the expression of exhaustion phenotype on CD4+ T cells A-C. and CD8+ T cells. (Continued) 


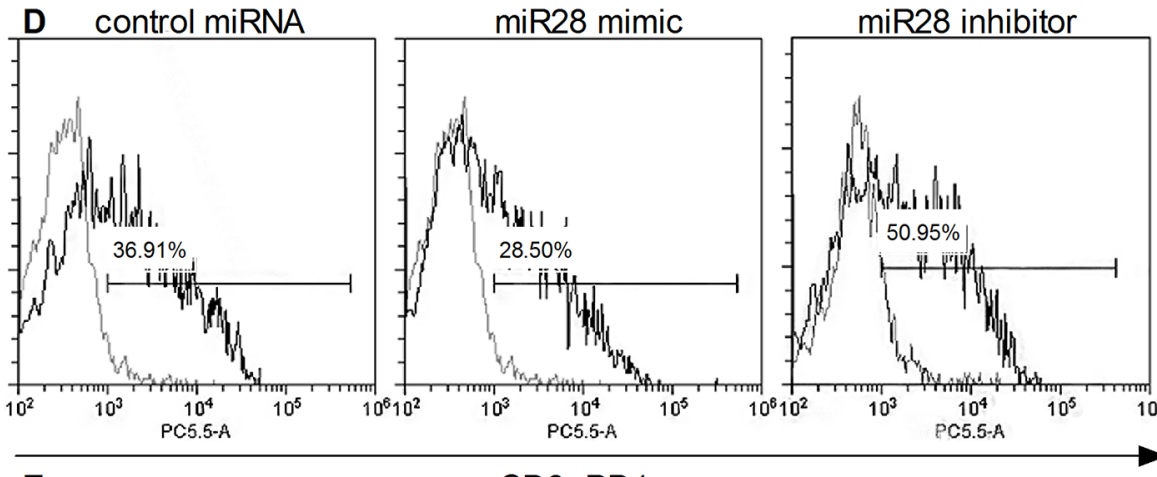

miR28 inhibitor

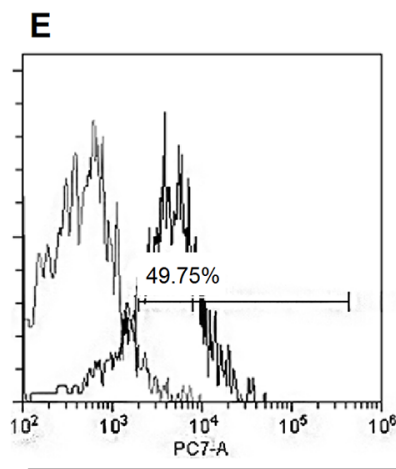

\section{CD8+PD1}
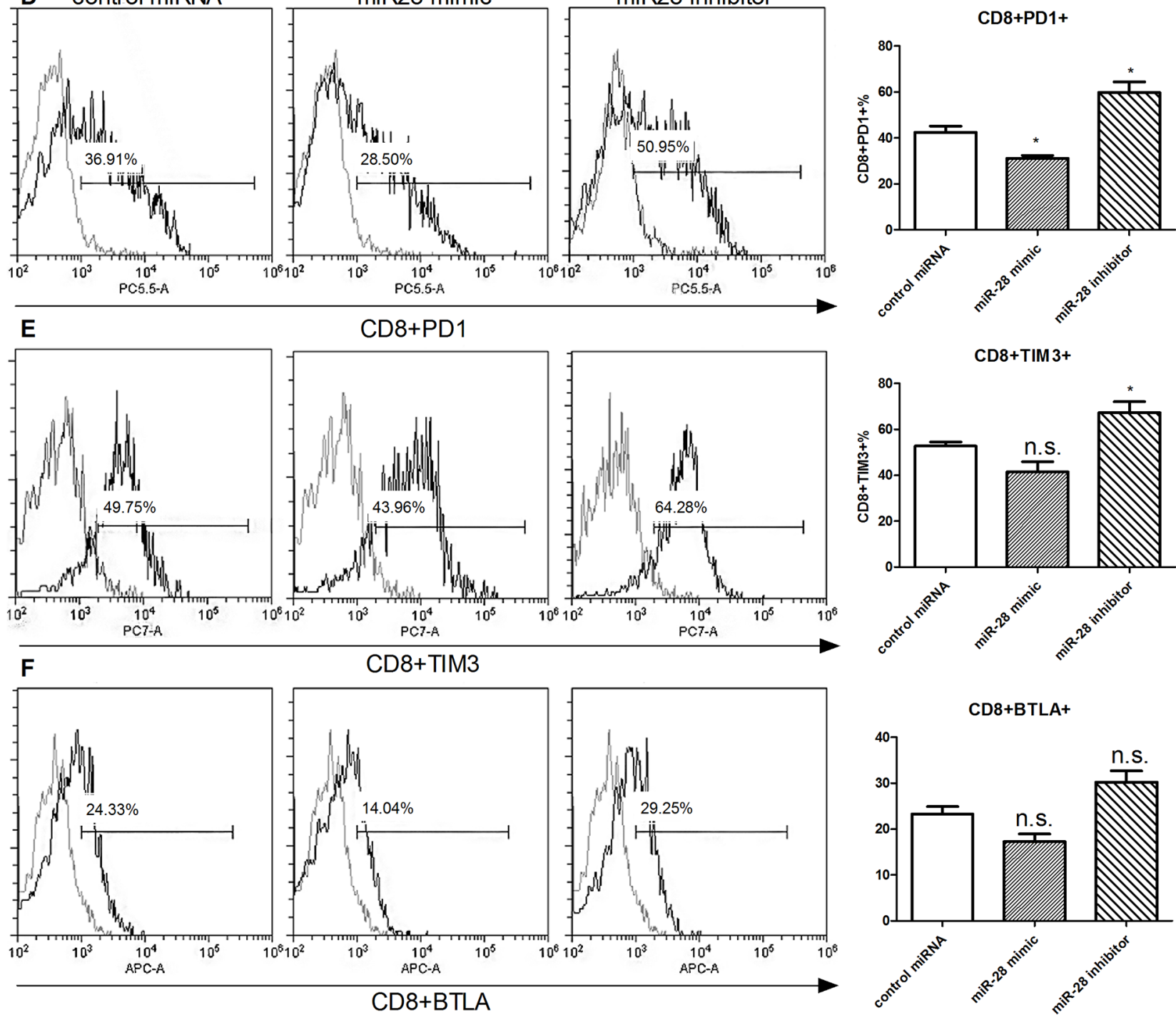

CD8+TIM3+
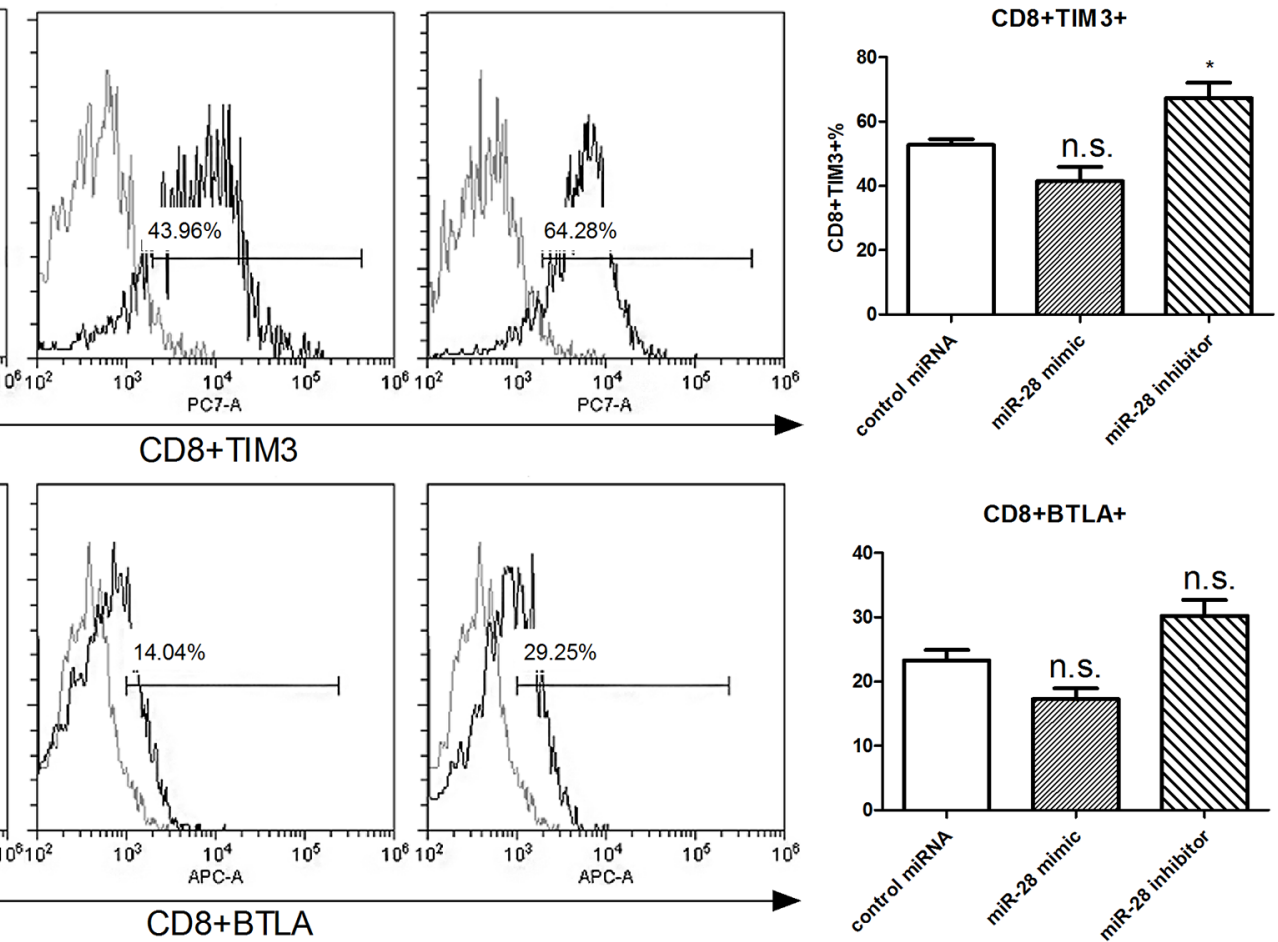

Figure 6: (Continued) Alteration of exhaustive phenotype of $T$ cells after transfection of miR-28 mimic and miR-28 inhibitor. D-F. Significance was assumed if $P<0.05$ using one-way analysis of variance followed by a Dunnett's multiple comparison test, and denoted as $*=P<0.05$ and $* *=P<0.01$. n.s. (not significant) means $P$ value was more than 0.05 . The date shown are representative of three independent experiments.

\section{miR-28 recovering the cytokine secretion of exhausted $T$ cells}

One of the characteristics of $\mathrm{T}$ cell exhaustion is impairing cytokine secretion by $\mathrm{T}$ cells [22]. To test whether miR-28 reverse the cytokine secretion of exhausted $\mathrm{T}$ cells, we collected $\mathrm{T}$ cells from the lymph nodes of B16F10-bearing mice, cultured in anti-CD3e coating plates, and transfected them with either miR28 mimic or inhibitor. The supernatant of $\mathrm{T}$ cells were collected to detect cytokines including interleukin-2 (IL-2) and tumor necrosis factor-a (TNF- $\alpha$ ) by enzyme-linked immune sorbent assay (ELISA). As shown in Figure 8, The concentration of IL-2 was increased from $18.62 \mathrm{pg} /$ $\mathrm{ml}$ to $24.87 \mathrm{pg} / \mathrm{ml}$ when transfected with miR-28 mimic compared with control miRNA (Figure 8A), and the TNF- $\alpha$ level was increased from $68.52 \mathrm{pg} / \mathrm{ml}$ to 103.6 $\mathrm{pg} / \mathrm{ml}$. On the contrary, the miR-28 inhibitor decreased the TNF- $\alpha$ secretion (Figure 8B). Our results indicate that miR-28 may convert the exhaustive status of $\mathrm{T}$ cells through recover the ability of $\mathrm{T}$ cell to secret cytokines such as IL-2 and TNF- $\alpha$.

\section{DISCUSSION}

$\mathrm{T}$ cell exhaustion is a status of $\mathrm{T}$ cell functional deficiency in cancer [23]. The $T$ cells progress through stages of dysfunction in tumor environment as the tumor antigen stimulate continuously [1], the dysfunctional $\mathrm{T}$ cells are fail to control the infection and the tumor cells. 
One of the main feature of exhausted $\mathrm{T}$ cells in cancer environment is overexpression of high levels of inhibitory receptors [4]. Researches indicated that exhausted CD8+ $\mathrm{T}$ cells up regulate multiple IRs, such as PD1, TIM3, BTLA $[6,24]$. Those IRs correlate with variable levels of $\mathrm{T}$ cell dysfunction. In this paper, we have examined five IRs PD1, TIM3, BTLA, 2B4, LAG3 which are used to characterize exhausted $\mathrm{T}$ cells. We compared those exhausted $\mathrm{T}$ cell phenotype on CD4+ or CD8+ T cells between naive and melanoma-bearing mice. We found that all those IRs were increased in the CD4+ or CD8+ T cells in tumor-bearing mice. Higher expression of those IRs were found in T cells isolated from lymph node than from spleen.
In order to demonstrate how silencing of PD1 affects the function of T cells, PD1 was induced in vitro since naive T cells express very low levels of PD1. Anti-CD3e was chosen to up-regulate PD1 in T cells based on previous studies that demonstrated anti-CD3e is able to successfully to induce PD1 and T cell anergy on $\mathrm{CD}^{+} \mathrm{T}$ cells [25]. Previous research reported that IFN- $\alpha$ can stimulate $\mathrm{T}$ cells declined in number and became exhausted, and stimulated $\mathrm{T}$ cells in the tumor expressed higher levels of PD1 inhibitory receptor [20]. In our study, we optimized the protocol to induce exhausted T cells using anti-CD3e. We detected the effect of various concentrations of antiCD3e antibodies and the effect of IFN- $\alpha$. We found that both anti-CD3e and anti-CD3e+IFN- $\alpha$ can induce
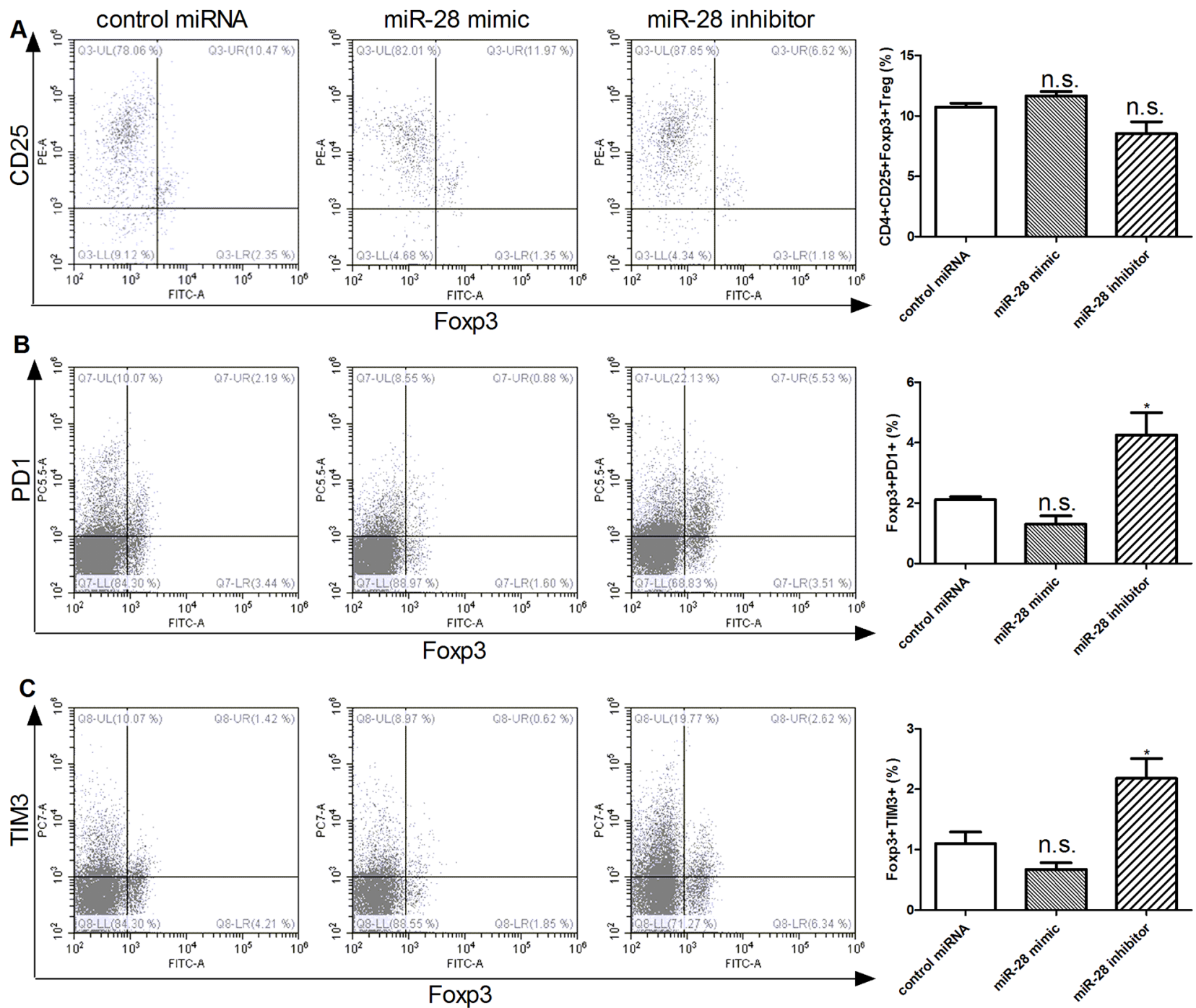

Figure 7: miR-28 regulating FoxP3+PD1+ and Foxp3+TIM3+ Treg cells. Two million lymphocytes, collected from lymph nodes of B16F10-bearing mice, were plated per well in a 24 well plate and transfected with $1 \mu \mathrm{g}$ of miR-28 mimic or miR-28 inhibitor, then cells were cultured with anti-CD3e $(10 \mu \mathrm{g} / \mathrm{ml})$ coating plates for $72 \mathrm{hrs}$. Flow cytometric analysis were performed to determine the subsets of conventional CD4+CD25+Foxp3+ Treg A. Foxp3+PD1+ T cells B. and C. Foxp3+TIM3+ T cells. The miRNA mimics or inhibitor group were compared to control group using an unpaired student's T test. Significance was assumed if the $P$ value was less than 0.05 (* $=P<0.05)$. n.s. (not significant) means $P$ value was more than 0.05 . The data shown are representative of at least three independent experiments. 
upregulation of inhibitory receptors in vitro. Not only PD1 were induced, the other IRs including TIM3, BTLA, 2B4 and LAG3 were increased as well. The concentration of anti-CD3e was positively correlated with the expression of those IRs within the range of $10 \mu \mathrm{g} / \mathrm{ml}$ and these was no remarkable difference in the expression of IRs between the concentrations of $10 \mu \mathrm{g} / \mathrm{ml}$ and $20 \mu \mathrm{g} / \mathrm{ml}$. For costeffectiveness, $10 \mu \mathrm{g} / \mathrm{ml}$ anti-CD3e Abs was chosen for in vitro experiments.

Until recently, $\mathrm{PD}-1$ has been recognized as the primary Biomarker for exhausted T cells, PD1/PD-L1 pathway has a vital role to regulate immunosurveillance for tumors [26]. Blocking the PD-1/PD-L1 pathway are promising approaches for enhancing antitumor immune responses to accelerate tumor eradication [27]. Zhang et al found that miR-4717 can binding to the 3'UTR of PD1 mRNA and influence the PD-1 expression, it will affect the occurrence and progress of chronic HBV infection, and also change the immune states [28]. In non-small cell cancer, P53 can regulates PD-L1 via miR-34, which directly binds to the PD-L1 3'UTR [29]. In our research, the PD1+ and PD1-CD4 T cells was sorted for the microarray assays to compare miRNA expression between those two groups of cells. Based on our microarray and qPCR results, three miRNA (miR-28, miR-150, miR-151$5 p)$ were confirmed decreased in CD4+PD1+ T cells. We postulated that the high expression of PD1 was associated with those three decreased miRNAs. Among the three miRNA, miR-28 has potential to bind to the 3'UTR of
PD1, TIM3 and BTLA. An dual luciferase assay was conducted for PD1 3'UTR and demonstrated that miR-28 can directly silence PD1 through binding to its 3'UTR, melanoma cell line B16F10 were choose for the luciferase experiment, the cell line are easier to transfected and the results are more stabilized. So miR-28 was selected as the candidate miRNA that fulfilled the objectives of this study. miR-28 mimic silenced the 3' UTR of PD1 and decreased PD1 expression. On the contrary, miR-28 inhibitors increased PD1, meanwhile, increased TIM3 and 2B4 expression.

Tumor infiltration of PD1 positive or Foxp3 positive lymphocytes, termed as exhaustive Treg cells, can used as significant prognostic indicators for clear cell renal cell carcinoma (CRCC). PD1 positivity and high number of Treg in a CRCC patient can predict poor overall survival of the patient [30]. Kaori Sakuishi et al also found that Foxp3+ Tregs in the tumor always express TIM3 and PD1. Those TIM3 + Tregs were activated in tumor environment, and have higher immunosuppressive activity [31]. The expression of the inhibitory molecules PD1 and LAG-3 was implicated in supporting Treg function $[32,33]$. In this study, we found that the presence of miR-28 inhibitor can induce the Foxp3+PD1+ and Foxp3+TIM+ Treg cell differentiation in vitro. The results suggested that miR- 28 can regulate the generation or differentiation of exhaustive Treg.

Changes in the cytokine production is a major feature of exhausted $\mathrm{T}$ cells in tumor microenvironment. IL-2, interferon (IFN- $\gamma$ ) and TNF- $\alpha$ are hyposecretion
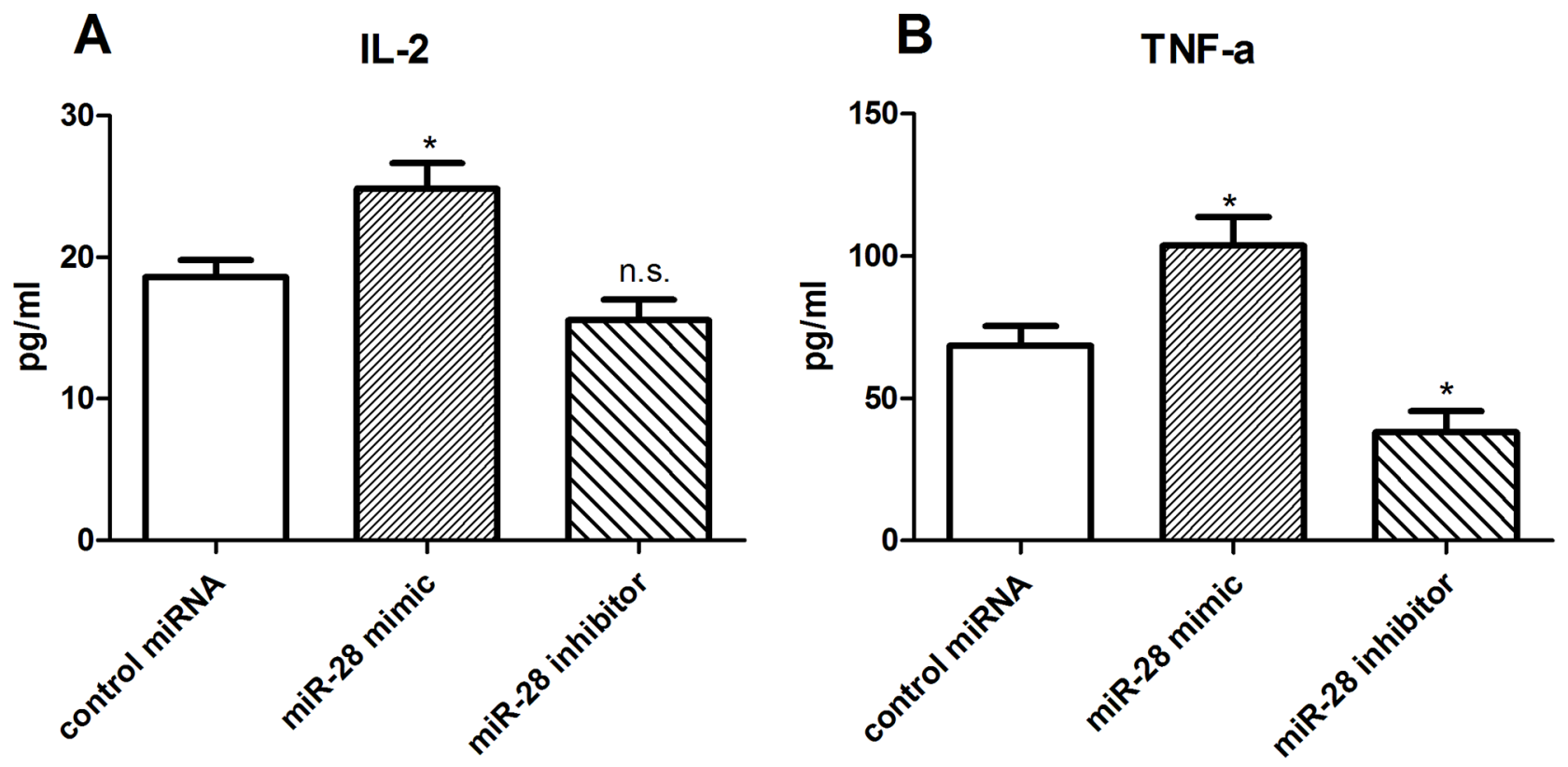

Figure 8: miR-28 modulating cytokine secretion of exhaustive $\mathbf{T}$ cells. Two million lymphocytes, collected from lymph nodes of B16F10-bearing mice, were plated per well in a 24 well plate and transfected with $1 \mu \mathrm{g}$ of miR-28 mimic or inhibitor, then cells were cultured with anti-CD3e $(10 \mu \mathrm{g} / \mathrm{ml})$ coating plates for $72 \mathrm{hrs}$. The supernatant of T cells were collected to detect the IL-2 A. and TNF- $\alpha$ B. using ELISA. Significance was assumed if $P<0.05$ by T test, and denoted as $*=P<0.05$, as comparing with control miRNA transfected cells. n.s. (not significant) means $P$ value was more than 0.05 . The date shown are representative of three independent experiments. 
during $\mathrm{T}$ cell exhaustion. The production of IL-2,

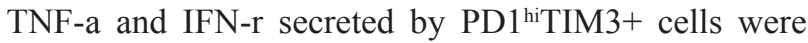
reduced in leukemia patients [34]. In addition, Other cytokines such as IL-10 and TFG- $\beta$ were also changed in $\mathrm{T}$ cells exhaustion $[1,22]$. PD1 signaling may contribute significantly to the declination of IL2 and TNF-a production [8]. It was reported that TNF- $\alpha$ was a powerful anticancer cytokine to mediate cancer-related inflammation [35]. Liu et al reported that combined targeting of PD1 and TIM3 pathways increased the frequencies of TNF- $\alpha[36]$. Blockage of the PD1/PD-L1 pathway in microglial can increase T-cell IFN- $\gamma$ and IL-2 production [37]. Our research, for the first time, found that miR-28 can manipulating the secretion of cytokines from exhausted T cells. Addition of miR-28 mimics increase the level of IL- 2 and TNF- $\alpha$ of T cells, suggesting another benefit of miR-28 that may restore the cytokine secretion function of exhausted $\mathrm{T}$ cells in tumor.

Most of researches were concerned about miR-28 and cancer cells in the past. In a non-immune cell related cancer, clear cell renal cell carcinoma, transfection with miR-28 mimic was shown to weaken mitotic checkpoint activation and to induce chromosomal instability by targeting MAD2L1[38]. However, miR-28 was found high expression in other tumors such as esophagus cancer [39], ovarian cancer [40] and renal cancer [41]. miR-28 levels were reduced in B cell lymphoma and re-expression of this miRNA leads to impaired cell proliferation through silenced MAD2L1, a component of cell cycle for mitotic spindle coordination [42]. In our study, miR-28 was proved beneficial to inhibit $\mathrm{T}$ cells exhaustion. It is the first time to illuminate the relationship between miR-28 and T cells in melanoma.

Most of the clinical success of immunotherapy to treat the cancer is based on the checkpoint modulatory antibodies [43]. In 2014, the first anti-PD1 antibody pembrolizumab was approved for patients to treat advanced metastatic melanoma. There still have a lot of clinical trials to evaluate the antibodies targeting the inhibitory receptors such as CTLA4, PD1, PDL1 and LAGs for the treatment of patients with different cancer [44]. To our knowledge, there has been no reported research to restore exhausted T cells by using miRNA. Our study expands the role of miR-28 to that of an indirect tumor suppressor by decreasing the phenotype of exhaustion and regulating the cytokine IL-2 and TNF- $\alpha$ secretion.

\section{MATERIALS AND METHODS}

\section{B16F10 cell culture}

B16F10 cells were obtained from ATCC (Manassas, VA). Cells were cultured using DMEM medium (Gibco, Life Technologies, Burlington, ON) made complete with 10\% fetal bovine serum (FBS; Gibco), $100 \mathrm{U} / \mathrm{ml}$ of penicillin (Gibco), and $100 \mu \mathrm{g} / \mathrm{ml}$ of streptomycin (Gibco) at $37^{\circ} \mathrm{C}$ in $5 \% \mathrm{CO}_{2}$.

\section{Melanoma mouse model}

Eight-ten week old C57BL/6 mice (Charles River Canada, Saint-Constant, Canada) were used to generate a melanoma mouse model. Animals were housed under conventional conditions at the Animal Care Facility, Western University, and were cared for in accord with guidelines established by the Canadian Council on Animal Care. Tumors were generated on the backs of each mouse by subcutaneous injection of $4 \times 10^{5}$ B16F10 cells in PBS (Gibco). Tumors were allowed to grow for 16 days or until reaching a size of 2,000 $\mathrm{mm}^{3}$. Mice were monitored daily and euthanized by $\mathrm{CO}_{2}$ inhalation.

\section{Lymphocyte isolation from lymph nodes and spleen}

Draining lymph nodes and spleens were obtained from tumor-bearing mice, lymph nodes and spleens were also isolated from naïve mice. Lymph nodes were pressed through a $40 \mu \mathrm{m}$ Falcon Cell Strainer (VWR, Mississauga, $\mathrm{ON}$ ) into RPMI 1640 medium (Gibco) and cells were counted and centrifuged for $5 \mathrm{~min}$ at $1,500 \mathrm{rpm} / 4^{\circ} \mathrm{C}$. Spleen cells were further isolated using ACK Lysing Buffer (Lonza) to lyse red blood cells.

\section{Cell sorting the CD4+PD1+ and CD4+PD1- cells}

$\mathrm{CD}^{4}+\mathrm{PD}^{+}$and $\mathrm{CD} 4+\mathrm{PD}^{-} \mathrm{T}$ cells were isolated from tumor-bearing mice using fluorescence-activated cell sorting. Cell sorting was performed using a BD FACS Aria III (BD Biosciences, Mississauga, ON) after stained with $0.2 \mu \mathrm{g}$ of CD8-FITC, CD4-PE, PD1-PerCP-eFluor 710, Rat IgG2b Isotype Control-PerCP-eFluor 710, or $0.1 \mu \mathrm{g}$ of Fixable Viability Dye eFluor 506 (eBioscience).

\section{miRNA extraction and cDNA synthesis}

Total RNA including miRNAs of sorting CD4+PD1+ and CD4+PD1- T cells was isolated using the miRNeasy Mini Kit (Qiagen, Toronto, ON) according to the manufacturer's instructions. RNA concentration was measured using a NanoDrop ND-1000 (Thermo Scientific, Ottawa, ON). RNA was reverse transcribed using the miScript II Reverse Transcriptase Kit (Qiagen).

\section{miRNA array analysis}

An Affymetrix GeneChip 3.0 miRNA Array (Affymetrix, Santa Clara, CA) was used with the FlashTag Biotin HSR RNA Labeling Kit (Affymetrix) according to the manufacturer's instructions. The array was scanned using the GeneChip Scanner 3000 and Affymetrix GeneChip Command Console software (Affymetrix) and analysis of miRNA data was performed using the Partek Genomics Suite (Partek, St. Louis, MO). All miRNA expression data have been submitted 
to the Gene Expression Omnibus microarray data repository (http://www.ncbi.nlm.nih.gov/geo/query/acc. cgi?acc=GSE65208, accession number GSE65208).

\section{Reverse transcription qPCR (RT-qPCR) for assessment of miRNA level}

RT-qPCR primers for those significantly altered miRNAs discovered from the miRNA array were purchased from Qiagen company (Qiagen). qPCR reactions were performed in a Stratagene Mx3000P QPCR System (Agilent Technologies, Lexington, MA) using the miScript SYBR green PCR Kit (Qiagen) and miScript Primer Assays (Qiagen). The PCR reaction conditions for miRNA analysis were $95^{\circ} \mathrm{C}$ for $15 \mathrm{~min}$ followed by 40 cycles of $94^{\circ} \mathrm{C}$ for $15 \mathrm{sec}, 55^{\circ} \mathrm{C}$ for $30 \mathrm{sec}$, and $70^{\circ} \mathrm{C}$ for $30 \mathrm{sec}$. miRNA primer was referenced to homo sapiens small nucleolar RNA, C/D box 61 and normalized to PD1cells using the $2^{-\Delta \Delta C t}$ method as described by Livak and Schmittgen [45].

\section{In silico analysis}

An in silico analysis was performed by accessing multiple miRNA databases: miRanda, TargetScan Mouse 6.2 and PicTar. In each database, miRNAs that had complementarity to the 3' UTRs of PD1, TIM3, and BTLA were searched. Only 7 mer or 8 mer miRNAs were considered.

\section{PD1 3' UTR pmirGLO dual luciferase plasmid synthesis}

The 3' UTR of PD1 was amplified from wild-type c57BL/6 lymphocyte cDNA using PCR with $10 \mu \mathrm{M}$ PD1 3' UTR forward and reverse primer:

Forward: 5'-ATATACTCGAGCCAGATTCTTCAG CCATTAGCATGCT

Reverse: 5'-GCGTGTCTAGATTTAAAGCTTTTG GTACCATTTAATTATAACGGGCT and Taq polymerase (Invitrogen). The amplified cDNA was separated on a $1.5 \%$ agarose gel and the QIAquick Gel Extraction Kit (Qiagen) was used to isolate the PD1 3' UTR cDNA. The PD1 3' UTR and pmirGLO Dual Luciferase Plasmid (Promega, USA) were cleaved with XhoI and XbaI restriction enzymes (New England Biolabs, Ipswich, $\mathrm{MA})$ and allowed to ligate overnight at $16^{\circ} \mathrm{C}$. The PD1 $3^{\prime}$ UTR pmirGLO Dual Luciferase Plasmid was amplified in JM109 cells (Promega, Madison, WI) and extracted using the GeneJET Plasmid Miniprep Kit (Fermentas, Burlington, ON). The concentration of the plasmid was then measured using a NanoDrop ND-1000. Sequencing for confirmation of successfully ligation was done using the BigDye Terminator v3.1 Cycle Sequencing Kit (Applied Biosystems, Foster City, CA) in an Applied Biosystems 3730 DNA Analyzer (Applied Biosystems).

\section{Dual luciferase assays and miRNA mimics}

The miR-28 mimics sequence (Qiagen) transfected with the PD1 3' UTR pmirGLO plasmid are as follows: 5'-AAGGAGCUCACAGUCUAUUGAG. AllStars Negative Control was used as miRNA mimic control (Qiagen \#SI03650318). B16F10 cells were transfected using Lipofectamine 2000 according to the manufacturer's instructions using a 1:2 ratio of miRNA + plasmid $(\mu \mathrm{g})$ : Lipofectamine $2000(\mu \mathrm{l})$. Cells were cultured in complete DMEM culture medium at $37^{\circ} \mathrm{C}$ and $5 \% \mathrm{CO}_{2}$ for $24 \mathrm{hrs}$ before analysis ina Lumat LB 9507 luminometer (Berthold Technologies, Oak Ridge, TN). The Dual-Luciferase Reporter Assay System (Promega) was used to detect firefly and renilla luciferase from the PD1 3' UTR pmirGLO plasmid. Luciferase activity (firefly luciferase/renilla luciferase) was normalized to the miRNA mimic control and PD1 3' UTR pmirGLO transfection.

\section{Lymphocytes treatment with anti-CD3e, CD3e+IFNa, CD3e+CD28}

Lymphocytes isolated from lymph nodes of $\mathrm{C} 57 \mathrm{BL} / 6$ mice were treated with anti-CD3e (BD Biosciences) or anti-CD3e+IFN- $\alpha$ (Pbl Assay Science, USA) or anti-CD3e+CD28 by plating $2 \times 10^{6}$ cells in each well in 24 well plates. The plates were coated with various concentrations (from $0-20 \mu \mathrm{g} / \mathrm{ml}$ ) of anti-CD3e in $200 \mu \mathrm{l}$ of PBS overnight at $4^{\circ} \mathrm{C}$. Plates were washed with PBS before lymphocytes were plated in Complete RPMI 1640. IFN- $\alpha(10 \mathrm{ng} / \mathrm{ml})$ or CD28 $(1 \mu \mathrm{g} / \mathrm{ml})$ was added to wells as indicated in results section at the time of plating. With all treatments, lymphocytes were incubated at $37^{\circ} \mathrm{C}$ and $5 \% \mathrm{CO}_{2}$ for $24 \mathrm{hrs}$ before cells were collected for flow cytometry.

\section{T cell transfection with miR-28 mimics and inhibitors}

Lymphocytes from the lymph nodes of B16F10bearing C57BL/6 mice were plated 2 million per well in a 24 well plate using $400 \mu \mathrm{l}$ of RPMI 1640 with $10 \%$ FBS and $50 \mathrm{mM}$ 2-ME (Transfection RPMI 1640 medium). One $\mu \mathrm{g}$ of miR-28 mimic/miR-28 inhibitor (controls, Qiagen \#SI03650318 and \#1027271) was added to 50 $\mu 1$ of Opti-MEM. Lipofectamine 2000 was added to separate tubes with $50 \mu 1$ of Opti-MEM at a 2:1 ratio of miRNA $(\mu \mathrm{g})$ : Lipofectamine $2000(\mu \mathrm{l})$. After 5 min incubation at room temperature, the contents of RNA and transfection reagent tubes were combined and incubated for $20 \mathrm{~min}$ at room temperature. The $100 \mu \mathrm{lmixture}$ was then added to each well. After $4 \mathrm{hrs}$ incubation at $37^{\circ} \mathrm{C}$ and $5 \% \mathrm{CO}_{2}$, an additional $500 \mu 1$ of RPMI 1640 medium containing $10 \%$ FBS and $50 \mathrm{mM} 2-\mathrm{ME}$ was added to each well and the plates were incubated for up to 72 
hrs at $37^{\circ} \mathrm{C}$ and $5 \% \mathrm{CO}_{2}$ before cells were collected for various experiments.

\section{PD1, TIM3 and BTLA gene expression}

cDNA was synthesized using oligo-(dT) primer and reverse transcriptase (Invitrogen) according to the manufacture's protocol. The primers for PD1, TIM3 and BTLA and GAPDH were synthesized by Invitrogen, the sequences of oligonucleotide primers were shown in Supplementary Table S1. qPCR reactions were conducted using the SensiFAST ${ }^{\mathrm{TM}}$ SYBR NO-ROX Kit (Bioline, USA). The PCR reaction conditions were $95^{\circ} \mathrm{C}$ for $2 \mathrm{~min}$ followed by 40 cycles of $95^{\circ} \mathrm{C}$ for $10 \mathrm{sec}, 58^{\circ} \mathrm{C}$ for $10 \mathrm{sec}$, and $72^{\circ} \mathrm{C}$ for $20 \mathrm{sec}$, then $95^{\circ} \mathrm{C}$ for $10 \mathrm{sec}$. Results were converted from cycle threshold $(\mathrm{Ct})$ values to transcript quantities follow the $2^{-\Delta \Delta \mathrm{Ct}}$ method with mouse glyceraldehyde-3-phosphate dehydrogenase (GAPDH) as the endogenous control for target gene expression. The levels of PD1, TIM3 and BTLA after transfected with miR-28 mimic or inhibitor were then expressed relative to that control miRNA group.

\section{Flow cytometry}

Flow cytometry was performed using a CytoFLEX $\mathrm{S}$ (Beckman Coulter Life Sciences, Mississauga, ON). Lymphocytes were stained with $0.2 \mu \mathrm{g}$ of CD4-FITC, CD8-FITC, PD1-PerCP-eFluor 710, TIM3-PE-CY7, BTLA-APC, 2B4-PE, LAG3-PE, Rat IgG2b Isotype Control-PerCP-eFluor 710, Mouse IgG2a K Isotype Control-PE, Mouse IgG1 K Isotype Control-APC, CD4PE-CY5, CD25-PE, Foxp3-FITC (eBioscience, San Diego, CA), or $0.1 \mu \mathrm{g}$ of Fixable Viability Dye eFluor 506 (eBioscience)based on the different experiment.

\section{Statistical analysis}

A two-tailed unpaired Student's T test was used to determine significance between two groups and a one-way analysis of variance for experiments with three or more groups. Details of control groups can be found in each figure legend. Significance was assumed at $P$ values < 0.05 .

\section{Abbreviations}

miRNA, microRNA; PD1, programmed death1;TIM3, T-cell immunoglobulin domain and mucin domain 3; BTLA, B- and T-lymphocyte attenuator; IRs, inhibitory receptors; Treg, regulatory T cells; 3'UTR, 3' untranslated regions.

\section{CONFLICTS OF INTEREST}

The author disclose no potential conflicts of interest.

\section{GRANT SUPPORT}

This study was partially supported by the grants from Natural Science Foundation of China (NSFC, No. 81160286, No. 91229119) and Jiangxi Science and Technology Innovation Programs (20124ACB00800, 20133BBG70019, 20135BBB70012), Graduate Student Innovation Funds of Nanchang University (YC2014-B024).

\section{REFERENCES}

1. Wherry EJ. T cell exhaustion. Nature immunology. 2011; 12:492-499.

2. Virgin HW, Wherry EJ and Ahmed R. Redefining chronic viral infection. Cell. 2009; 138:30-50.

3. Crawford A and Wherry EJ. The diversity of costimulatory and inhibitory receptor pathways and the regulation of antiviral $\mathrm{T}$ cell responses. Current opinion in immunology. 2009; 21:179-186.

4. Jiang Y, Li Y and Zhu B. T-cell exhaustion in the tumor microenvironment. Cell death \& disease. 2015; 6:e1792.

5. Matsuzaki J, Gnjatic S, Mhawech-Fauceglia P, Beck A, Miller A, Tsuji T, Eppolito C, Qian F, Lele S, Shrikant $\mathrm{P}$, Old LJ and Odunsi K. Tumor-infiltrating NY-ESO-1specific CD8+ T cells are negatively regulated by LAG-3 and PD-1 in human ovarian cancer. Proceedings of the National Academy of Sciences of the United States of America. 2010; 107:7875-7880.

6. Fourcade J, Sun Z, Benallaoua M, Guillaume P, Luescher IF, Sander C, Kirkwood JM, Kuchroo V and Zarour HM. Upregulation of Tim-3 and PD-1 expression is associated with tumor antigen-specific CD8+ T cell dysfunction in melanoma patients. The Journal of experimental medicine. 2010; 207:2175-2186.

7. Blank C and Mackensen A. Contribution of the PD-L1/PD-1 pathway to T-cell exhaustion: an update on implications for chronic infections and tumor evasion. Cancer immunology, immunotherapy : CII. 2007; 56:739-745.

8. Keir ME, Butte MJ, Freeman GJ and Sharpe AH. PD-1 and its ligands in tolerance and immunity. Annual review of immunology. 2008; 26:677-704.

9. Freeman GJ, Long AJ, Iwai Y, Bourque K, Chernova T, Nishimura H, Fitz LJ, Malenkovich N, Okazaki T, Byrne MC, Horton HF, Fouser L, Carter L, Ling V, Bowman MR, Carreno BM, et al. Engagement of the PD-1 immunoinhibitory receptor by a novel B7 family member leads to negative regulation of lymphocyte activation. The Journal of experimental medicine. 2000; 192:1027-1034.

10. Brahmer JR, Drake CG, Wollner I, Powderly JD, Picus J, Sharfman WH, Stankevich E, Pons A, Salay TM, McMiller TL, Gilson MM, Wang C, Selby M, Taube JM, Anders R, Chen L, et al. Phase I study of single-agent anti-programmed death-1 (MDX-1106) in refractory solid tumors: safety, clinical activity, pharmacodynamics, and immunologic correlates. Journal of clinical oncology : official journal 
of the American Society of Clinical Oncology. 2010; 28:3167-3175.

11. Kyi $\mathrm{C}$ and Postow MA. Checkpoint blocking antibodies in cancer immunotherapy. FEBS Lett. 2014; 588:368-376.

12. Momtaz $P$ and Postow MA. Immunologic checkpoints in cancer therapy: focus on the programmed death-1 (PD-1) receptor pathway. Pharmacogenomics and personalized medicine. 2014; 7:357-365.

13. Menzies AM and Long GV. New combinations and immunotherapies for melanoma: latest evidence and clinical utility. Ther Adv Med Oncol. 2013; 5:278-285.

14. Lu J, Lee-Gabel L, Nadeau MC, Ferencz TM and Soefje SA. Clinical evaluation of compounds targeting PD-1/ PD-L1 pathway for cancer immunotherapy. J Oncol Pharm Pract. 2014; doi:10.1177/1078155214538087.

15. Bartel DP. MicroRNAs: genomics, biogenesis, mechanism, and function. Cell. 2004; 116:281-297.

16. Perera RJ and Ray A. MicroRNAs in the search for understanding human diseases. BioDrugs : clinical immunotherapeutics, biopharmaceuticals and gene therapy. 2007; 21:97-104.

17. Eulalio A, Huntzinger E and Izaurralde E. Getting to the root of miRNA-mediated gene silencing. Cell. 2008; 132:9-14.

18. Furer V, Greenberg JD, Attur M, Abramson SB and Pillinger $\mathrm{MH}$. The role of microRNA in rheumatoid arthritis and other autoimmune diseases. Clinical immunology. 2010; 136:1-15.

19. Shin KH, Bae SD, Hong HS, Kim RH, Kang MK and Park NH. miR-181a shows tumor suppressive effect against oral squamous cell carcinoma cells by downregulating K-ras. Biochemical and biophysical research communications. 2011; 404:896-902.

20. Gerner MY, Heltemes-Harris LM, Fife BT and Mescher MF. Cutting edge: IL-12 and type I IFN differentially program CD8 T cells for programmed death 1 re-expression levels and tumor control. Journal of immunology. 2013; 191:1011-1015.

21. Sun S, Fei X, Mao Y, Wang X, Garfield DH, Huang O, Wang J, Yuan F, Sun L, Yu Q, Jin X, Wang J and Shen K. PD-1(+) immune cell infiltration inversely correlates with survival of operable breast cancer patients. Cancer immunology, immunotherapy : CII. 2014; 63:395-406.

22. Balkhi MY, Ma Q, Ahmad S and Junghans RP. T cell exhaustion and Interleukin 2 downregulation. Cytokine. 2015; 71:339-347.

23. Patsoukis N, Bardhan K, Chatterjee P, Sari D, Liu B, Bell LN, Karoly ED, Freeman GJ, Petkova V, Seth P, Li L and Boussiotis VA. PD-1 alters T-cell metabolic reprogramming by inhibiting glycolysis and promoting lipolysis and fatty acid oxidation. Nature communications. 2015; 6:6692.

24. Fourcade J, Sun Z, Pagliano O, Guillaume P, Luescher IF, Sander C, Kirkwood JM, Olive D, Kuchroo V and Zarour HM. CD8(+) T cells specific for tumor antigens can be rendered dysfunctional by the tumor microenvironment through upregulation of the inhibitory receptors BTLA and PD-1. Cancer research. 2012; 72:887-896.

25. Bishop KD, Harris JE, Mordes JP, Greiner DL, Rossini AA, Czech MP and Phillips NE. Depletion of the programmed death-1 receptor completely reverses established clonal anergy in CD4(+) T lymphocytes via an interleukin-2dependent mechanism. Cell Immunol. 2009; 256:86-91.

26. Merelli B, Massi D, Cattaneo L and Mandala M. Targeting the PD1/PD-L1 axis in melanoma: biological rationale, clinical challenges and opportunities. Critical reviews in oncology/hematology. 2014; 89:140-165.

27. Okazaki T, Chikuma S, Iwai Y, Fagarasan S and Honjo T. A rheostat for immune responses: the unique properties of PD-1 and their advantages for clinical application. Nature immunology. 2013; 14:1212-1218.

28. Zhang G, Li N, Li Z, Zhu Q, Li F, Yang C, Han Q, Lv Y, Zhou Z and Liu Z. microRNA-4717 differentially interacts with its polymorphic target in the PD1 3' untranslated region: A mechanism for regulating $\mathrm{PD}-1$ expression and function in $\mathrm{HBV}$-associated liver diseases. Oncotarget. 2015; 6:18933-18944.

29. Cortez MA, Ivan C, Valdecanas D, Wang X, Peltier HJ, Ye Y, Araujo L, Carbone DP, Shilo K, Giri DK, Kelnar K, Martin D, Komaki R, Gomez DR, Krishnan S, Calin GA, et al. PDL1 Regulation by p53 via miR-34. Journal of the National Cancer Institute. 2016; 108.

30. Kang MJ, Kim KM, Bae JS, Park HS, Lee H, Chung MJ, Moon WS, Lee DG and Jang KY. Tumor-infiltrating PD1Positive Lymphocytes and FoxP3-Positive Regulatory T Cells Predict Distant Metastatic Relapse and Survival of Clear Cell Renal Cell Carcinoma. Translational oncology. 2013; 6:282-289.

31. Sakuishi K, Ngiow SF, Sullivan JM, Teng MW, Kuchroo VK, Smyth MJ and Anderson AC. TIM3FOXP3 regulatory $\mathrm{T}$ cells are tissue-specific promoters of T-cell dysfunction in cancer. Oncoimmunology. 2013; 2:e23849.

32. Francisco LM, Sage PT and Sharpe AH. The PD-1 pathway in tolerance and autoimmunity. Immunological reviews. $2010 ; 236: 219-242$.

33. Huang CT, Workman CJ, Flies D, Pan X, Marson AL, Zhou G, Hipkiss EL, Ravi S, Kowalski J, Levitsky HI, Powell JD, Pardoll DM, Drake CG and Vignali DA. Role of LAG-3 in regulatory T cells. Immunity. 2004; 21:503-513.

34. Kong Y, Zhang J, Claxton DF, Ehmann WC, Rybka WB, Zhu L, Zeng H, Schell TD and Zheng H. PD-1(hi)TIM-3(+) $\mathrm{T}$ cells associate with and predict leukemia relapse in AML patients post allogeneic stem cell transplantation. Blood cancer journal. 2015; 5:e330.

35. Balkwill F. Tumour necrosis factor and cancer. Nature reviews Cancer. 2009; 9:361-371.

36. Liu J, Zhang S, Hu Y, Yang Z, Li J, Liu X, Deng L, Wang Y, Zhang X, Jiang T and Lu X. Targeting PD-1 and Tim-3 Pathways to Reverse CD8 T-Cell Exhaustion and Enhance 
Ex Vivo T-Cell Responses to Autologous Dendritic/Tumor Vaccines. Journal of immunotherapy. 2016; 39:171-180.

37. Schachtele SJ, Hu S, Sheng WS, Mutnal MB and Lokensgard JR. Glial cells suppress postencephalitic CD8+ T lymphocytes through PD-L1. Glia. 2014; 62:1582-1594.

38. Hell MP, Thoma CR, Fankhauser N, Christinat Y, Weber TC and Krek W. miR-28-5p promotes chromosomal instability in VHL-associated cancers by inhibiting Mad2 translation. Cancer Res. 2014; 74:2432-2443.

39. Liu SG, Qin XG, Zhao BS, Qi B, Yao WJ, Wang TY, Li HC and Wu XN. Differential expression of miRNAs in esophageal cancer tissue. Oncology letters. 2013; 5:1639-1642.

40. Wilting SM, Snijders PJ, Verlaat W, Jaspers A, van de Wiel MA, van Wieringen WN, Meijer GA, Kenter GG, Yi Y, le Sage C, Agami R, Meijer CJ and Steenbergen RD. Altered microRNA expression associated with chromosomal changes contributes to cervical carcinogenesis. Oncogene. 2013; 32:106-116.

41. Wotschofsky Z, Meyer HA, Jung M, Fendler A, Wagner I, Stephan C, Busch J, Erbersdobler A, Disch AC,
Mollenkopf HJ and Jung K. Reference genes for the relative quantification of microRNAs in renal cell carcinomas and their metastases. Analytical biochemistry. 2011; 417:233-241.

42. Schneider C, Setty M, Holmes AB, Maute RL, Leslie CS, Mussolin L, Rosolen A, Dalla-Favera R and Basso K. MicroRNA 28 controls cell proliferation and is downregulated in B-cell lymphomas. Proceedings of the National Academy of Sciences of the United States of America. 2014; 111:8185-8190.

43. Hoos A. Development of immuno-oncology drugs - from CTLA4 to PD1 to the next generations. Nature reviews Drug discovery. 2016; 15:235-247.

44. Verdeil G, Fuertes Marraco SA, Murray T and Speiser DE. From T cell "exhaustion" to anti-cancer immunity. Biochimica et biophysica acta. 2016; 1865:49-57.

45. Livak KJ and Schmittgen TD. Analysis of relative gene expression data using real-time quantitative PCR and the 2(-Delta Delta C(T)) Method. Methods (San Diego, Calif). $2001 ; 25: 402-408$. 